\title{
O (DES)CONHECIMENTO RECÍPROCO DOS INVESTIGADORES IBERo-AMERICANOS DE Cî̂NCIAS dA COMUniCAÇÃo
}

\author{
Paulo Serra
}

\begin{abstract}
RESUMO
Este texto apresenta e discute os resultados da análise de conteúdo realizada a uma amostra de revistas de Ciências da Comunicação de Portugal, do Brasil e de Espanha e cujo objetivo consistiu em avaliar o grau de conhecimento - ou desconhecimento - mútuo dos investigadores daqueles três países. Essa análise incidiu, nomeadamente, na nacionalidade dos autores que publicaram artigos nessas revistas e dos outros autores que indicaram como referências nesses artigos.
\end{abstract}

Palavras-chave

Revistas; ciências da comunicação; Portugal; Brasil; Espanha

\section{INTRODUÇÃo}

A língua é apontada, a justo título, como um dos grandes obstáculos à comunicação universal da ciência - uma comunicação universal indispensável à universalidade que, desde Aristóteles, é reconhecida como uma das características essenciais do saber científico e que o distinguem de saberes como o senso comum e a Filosofia, ou de práticas como as artes e os ofícios.

$\mathrm{Na}$ impossibilidade de uma língua universal, muito bem justificada por Descartes na sua célebre carta a Mersenne de 20 de novembro de 1629, a solução encontrada ao longo da história tem sido a da instituição de "línguas francas" - o latim até praticamente ao século XIX, o inglês sobretudo a partir de meados do século XX.

A instituição do inglês como "língua franca" é perspetivada, geralmente, como um dos maiores obstáculos à difusão e circulação internacionais dos artigos publicados pelos autores em português e espanhol da área de Ciências da Comunicação. No entanto, resta saber se publicar em português e espanhol será garantia de que se seja lido e conhecido pelos investigadores falantes de português e espanhol. Para averiguar se os autores de língua portuguesa e espanhola tendem a referenciar mais os autores que publicam nessas mesmas línguas, ou se, pelo contrário, todos eles se desconhecem, resolvemos proceder a um estudo exploratório centrado na análise de conteúdo de uma amostra de revistas de Ciências da Comunicação de Portugal, Brasil e Espanha. São os resultados desse estudo que apresentamos e discutimos nos pontos que se seguem. 


\section{A CIÊNCIA COMO ARGUMENTAÇÃo}

Em texto recente, Martins (2015) sublinhava a gradual subvalorização, quase obliteração, na tradição cultural do Ocidente, das palavras em favor dos números, da retórica em favor da ciência e da tecnociência.

A revalorização do primeiro dos polos exige, $a b$ initio, uma visão da ciência como assente, ela própria, na retórica e na argumentação (Santos, 1993, 2002). Entendida a ciência desse modo, a "objetividade científica" mais não será do que "a disponibilidade [dos cientistas] para a crítica mútua" (Popper, 1999, p. 122), e o método da ciência - que não difere, nesse aspeto, do das outras formas de conhecimento - o método da "discussão crítica", assente em três passos fundamentais: problemas, teorias e críticas (Popper, 1999, p. 131).

Se concebermos a ciência como assentando, ela própria, num processo de argumentação, então, podemos dizer que tanto podemos argumentar com palavras como com números, ou seja, que os números são apenas um dos meios possíveis de persuasão. Mesmo nas ciências mais formalizadas, como é o caso das Matemáticas, a palavra não pode ser dispensada. Ao mesmo tempo, sabemos que as Ciências Sociais e as Humanidades usam, frequentemente, a matemática para defender as suas teses.

A conceção de ciência como argumentação pode, também, permitir conciliar a distinção feita por Dilthey (1994) entre "ciências da natureza" (Naturwissenschaften) e "ciências do espírito" (Geisteswissenschaften), entre explicação e compreensão - na medida em que cada um destes pares exige sempre argumentação, ainda que com recurso a diferentes tipos de argumentos (cf. Ricouer, 1995).

Esta conceção de ciência como argumentação permite ainda ultrapassar a distinção clássica entre empirismo e racionalismo, entre "verdades de facto" e "verdades de razão" (Leibniz) - não só porque, como mostrou Kant, nos factos já está imersa a própria razão, mas também porque a razão só pode ganhar conteúdo com os factos: "pensamentos sem conteúdo são vazios; intuições sem conceitos são cegas" (Kant, 2001, p. 115). O logos da razão é também o da palavra. Como diz Gil (1989, p. 199), "a língua pensa", isto é, a categorialização da experiência - condição sine qua non da própria experiência - está na origem da categorialização da própria língua, pelo que uma e outra partilham as (mesmas) categorias. Pensar os factos é, pois, traduzi-los em palavras, umas ou outras, umas em vez de outras.

Assim, a conhecida afirmação de que "contra factos, não há argumentos", desconhece que há todo um conjunto de premissas argumentativas baseadas em factos, e que esses factos devem ser aceites por todos como tal para que as conclusões decorrentes possam ser aceites por todos.Por conseguinte, o que se entende por "facto" decorre, ele próprio, de um processo argumentativo (Perelman, 1993).

Uma argumentação envolve, como se sabe, uma questão, uma tese ou conclusão sobre essa questão, e um conjunto de premissas que suportam logicamente essa tese ou conclusão.

No nosso caso, a questão pode ser enunciada da seguinte forma: será que os investigadores de Ciências da comunicação que partilham o espaço ibero-americano, isto 
é, falantes de português e espanhol, se citam mais uns aos outros do que a cientistas que usam línguas que não essas, nomeadamente o inglês? Será que, sendo eles muitas vezes críticos da predominância (quase exclusividade) do inglês como língua de publicação científica, dão um exemplo de luta contra essa mesma predominância? Ou, pelo contrário, contribuem também para manter, reforçar e alargar essa predominância numa espécie de paródia daquilo a que, num outro contexto, Hegel chamou "a dialética do senhor e do escravo"?

Em relação a esta questão, a nossa tese de partida - uma tese baseada em impressões decorrentes da nossa própria experiência de leitor de artigos e outros textos científicos, de participante em congressos e outros eventos da área de Ciências da Comunicação - ia no sentido de que os falantes de português e espanhol se citam pouco entre si e citam, sobretudo, cientistas de língua inglesa (ingleses e estadunidenses).

\section{A PUBLICAÇÃo CIENTÍfICA E O REGRESSO DO AUTOR}

Curiosamente, ao mesmo tempo que se afirma que na ciência não há sujeito - no sentido em que o sujeito da ciência é anónimo e coletivo, e que o que mais importa é o resultado, não o seu produtor - e em que há muito se afirmou a "morte do autor" (Barthes, 1968; Foucault, 2001), a publicação científico-académica tem vindo a revalorizar, cada vez mais, a figura do autor e da autoria.

Ora, esta situação contrasta com aquela que, até uma época relativamente recente, era ainda a nossa. De facto, como observa Foucault, se na Idade Média os textos "literários" eram aceites sem referência ao autor, enquanto os textos "científicos" tinham de ser referidos à "autoridade" do seu autor (Hipócrates, por exemplo), já a partir dos séculos XVII e XVIII dá-se um verdadeiro "quiasma": os textos científicos remetem-se ao anonimato, enquanto os literários passam a exigir a indicação do seu autor (Foucault, 2001).

Em nosso entender, o "regresso" do autor à publicação científica deve-se, no essencial, não a uma qualquer necessidade intrínseca à ciência, mas à exigência académica e institucional de medir a produtividade do cientista-académico, em ordem a classificá-lo e, eventualmente, a premiá-lo - com dinheiro, promoções, prémios ou outros incentivos -, em função dessa produtividade. $O$ início dessa exigência pode situar-se no século XX, designadamente a partir da II Guerra Mundial - uma altura em que em países como os EUA se assiste ao triunfo de um modelo de investigação subordinada à lógica capitalista: especializado, concorrencial e orientado para os resultados práticos, sobretudo económicos. As instituições de investigação - universidades, institutos, etc. - transformam-se em autênticas empresas, competindo num mercado em que oferecem os seus produtos a outros tipos de empresas. Neste contexto, e para parafrasearmos a fórmula de Lasswell - que está longe de ser aplicar exclusivamente à comunicação - há que saber quem produz o quê, como, para quem e com que efeitos - de forma a ser devidamente recompensado ou, se for o caso, punido.

Como analisou muito bem Garfield, precisamente na mesma época em que se dá a industrialização da ciência, uma das formas mais objetivas de avaliação do trabalho de 
um cientista é o seu "fator de impacto", ou seja, "a significância de um trabalho particular e o seu impacto na literatura e no pensamento do período " (Garfield, 1955, p. 109) sendo tal "significância" medida em termos das citações que o cientista obtém por parte dos seus pares cientistas (e aqui estamos, mais uma vez, no domínio do número). É certo que Garfield via, no seu "índice de citação", sobretudo uma forma de os cientistas terem acesso, mais facilmente, por um lado, ao impacto do seu trabalho na comunidade científica e, por outro lado, ao conhecimento daquilo que de mais significativo ia sendo publicado por essa comunidade.

Mesmo que contestemos muitas das implicações teóricas e práticas da teoria de Garfield sobre a publicação científica - nomeadamente a sua ideia de que a publicação científica é sinónimo de artigos publicados em revistas em língua inglesa, devidamente indexadas em função das citações que obtêm por parte de artigos de outras revistas -, poderíamos aceitar, em princípio, que o sistema de citação é um fator essencial na avaliação do impacto ou visibilidade de uma certa publicação. No entanto, várias décadas depois, esse índice deslocou-se das revistas para os investigadores, do impacto (visibilidade) do trabalho para a sua importância, de mecanismo de informação para mecanismo de avaliação. Ou seja, passou a fazer parte, a ser mesmo o elemento essencial do sistema produtivista e capitalista que domina a produção e a distribuição da ciência pelo menos desde meados do século XX.

É precisamente neste contexto que se coloca a nossa questão: dentro de uma lógica garfieldiana, a probabilidade de um cientista falante de inglês citar um cientista de língua portuguesa ou espanhola - ou de qualquer outra língua que não a sua - é praticamente nula; e, ao mesmo tempo, a probabilidade de um cientista falante de português ou espanhol citar um cientista de língua inglesa é muito elevada. Resta saber, no entanto, qual é a probabilidade de os cientistas falantes de português ou espanhol se citarem entre si.

\section{A PROdUÇÃo CIENTÍfiCA PORTUGUESA}

A nossa questão ganha ainda mais sentido quando observamos as estatísticas referentes à publicação científica portuguesa nos últimos anos.

Os dados estatísticos da Pordata' referentes a essa publicação no período 19812013 mostram as seguintes tendências:

1. Um aumento exponencial do total de publicações e, dentro destas, dos artigos de revista, que aumentaram muito mais que as outras formas de publicação (resumos de comunicações, atas e "outros", não identificados).

2. Um aumento exponencial do número de publicações científicas, de publicações científicas citadas e de citações - mas que, a contracorrente, evidencia uma queda do número de publicações citadas a partir de 2012 e do número de citações a partir de 2008.

3. Um aumento exponencial dos artigos em coautoria, com destaque para coautores de países como Espanha, os EUA e o Reino Unido, mas também significativo em relação ao Brasil.

\footnotetext{
' Informação disponível em http://www.pordata.pt/Subtema/Portugal/Publicacoes+Cientificas-83. Estes dados baseiam-se, por sua vez, nos dados da DGEEC - Direção-Geral de Estatísticas da Educação e Ciência disponíveis em www.dgeec. mec.pt.
} 
Note-se, no entanto, que os dados em questão foram obtidos pelo InCitesTM, da Thomson Reuters (2014). Como esclarece a Pordata:

O InCitesTM, produto da Thomson Reuters, contém todos os registos bibliográficos que possuam pelo menos um endereço de autor com uma afiliação portuguesa e é elaborado a partir das bases de dados da Web of Science: Science Citation Index-Expanded ( $\mathrm{SCl}$ ), Social Science Citation Index (SSCl), Arts \& Humanities Citation Index $(\mathrm{AHCl})$, Conference Proceedings Citation Index-Science (CPCI-S), Conference Proceedings Citation Index-Social Science \& Humanities (CPCI-SSH). (Pordata, 2015)

Ao utilizar esta fonte de dados, a Pordata e a DGEEC, que lhe serve de fonte primária, acabam por validar acriticamente aquilo a que chamámos, mais atrás, o paradigma dominante na publicação científica: um paradigma que exclui da ciência outras línguas que não o inglês, outros tipos de publicações que não os artigos ou as atas de conferências, em suma, tudo aquilo que não for indexado nestas bases de dados específicas. Assim, são os próprios organismos nacionais, públicos e privados, a legitimar - com números - este verdadeiro processo de glotofagia e destruição cultural.

Ora, isto coloca mais uma vez a questão de saber como se situam os investigadores portugueses de Ciências da Comunicação perante este panorama, que tende a ser altamente penalizador para eles, dado que não são falantes nativos do Inglês (english native speakers), não publicam artigos sobre uma realidade (supostamente) universal e não dominam os corpos editoriais das grandes revistas anglo-americanas.

\section{Metodologia}

Para fundamentar a nossa tese de que os investigadores de Ciências da Comunicação falantes de português e espanhol se citam pouco entre si e citam, sobretudo, cientistas de língua inglesa (ingleses e estadunidenses), decidimos fazer uma análise de conteúdo dos artigos de uma amostra de revistas científicas da área publicadas em Portugal (3), no Brasil (3) e em Espanha (2). O número mais reduzido de revistas de Espanha justificou-se pelo facto de essas revistas publicarem um maior número relativo de artigos por edição.

As revistas e os números objeto de análise foram as seguintes:

Portugal

- Comunicação e Sociedade (U. Minho), $\mathrm{N}^{\circ} 25,1^{\circ}$ semestre de 2014

- Estudos em Comunicação (UBI), № 16, $1^{\circ}$ semestre de 2014

- Prisma (U. Porto e U. Aveiro), $N^{\circ} 24,1^{\circ}$ semestre de 2014

Brasil

- Contemporanea (UFBA), Vol. 12, $\mathrm{N}^{\circ} 1,1^{\circ}$ quadrimestre de 2014

- Eco-Pós (UFRJ), Vol. 17, $\mathrm{N}^{\circ} 1,1^{\circ}$ quadrimestre de 2014

- Matrizes (USP), Vol. 8, $\mathrm{N}^{\circ} 1,1^{\circ}$ quadrimestre de 2014 


\section{Espanha}

- Comunicación y Sociedad (U. Navarra), Vol. 27, $\mathrm{N}^{\circ} 1,1^{\circ}$ trimestre de 2014

- Comunicar (U. Huelva), Vol. XXI, $\mathrm{N}^{\circ} 42,1^{\circ}$ semestre de 2014

$\mathrm{Na}$ base da escolha deste corpus estiveram os seguintes critérios:

- Revistas com edições online (ainda que, nalguns casos, também tenham edições impressas);

- Revistas de caráter generalista, não dedicadas exclusivamente a determinados tópicos da área das Ciências da Comunicação (ainda que, nalgumas ocasiões, publiquem números dedicados a temas específicos);

- Revistas prestigiadas e relevantes em cada um dos países em causa;

- Números de revistas publicados sensivelmente no mesmo período.

As oito revistas publicaram, no número analisado, um total de 93 artigos, distribuídos conforme se apresenta na Tabela 1, abaixo:

\begin{tabular}{|c|c|c|c|}
\hline País & REVISTA & FREQUÊNCIA & Percentagem \\
\hline \multirow{4}{*}{ Portugal } & Comunicação e Sociedade & 12 & 12,9 \\
\hline & Estudos em Comunicação & 7 & 7,5 \\
\hline & Prisma & 7 & 7,5 \\
\hline & Subtotal & 26 & 27,9 \\
\hline \multirow{4}{*}{ BrasIL } & Contemporanea & 14 & 15,1 \\
\hline & Eco-Pós & 8 & 8,6 \\
\hline & Matrizes & 15 & 16,1 \\
\hline & Subtotal & 37 & 39,8 \\
\hline \multirow{4}{*}{ ESPANHA } & Comunicación y Sociedad & 10 & 10,8 \\
\hline & Comunicar & 20 & 21,5 \\
\hline & Subtotal & 30 & 32,3 \\
\hline & Total & 93 & 100,0 \\
\hline
\end{tabular}

Tabela1: Artigos por revista

Cada artigo, classificado inicialmente por país e revista foi, depois, analisado em função das seguintes categorias (indicam-se entre parênteses, as abreviaturas usadas nalguns casos):

Línguas

- Línguas do resumo

- Línguas do texto

Autor

- Autor de Portugal (AutPort)

- Autor do Brasil (AutBrasil)

- Autor de Espanha (AutEsp)

- Autor de Hispano-América (AutlHispAm)

- Autor de outra língua/localização, em regra de língua inglesa (AutOutro) 


\section{Referências}

- $\quad$ Referência de autor de Portugal (RefPort)

- Referência de autor do Brasil (RefBrasil)

- Referência de autor de Espanha (RefEsp)

- Referência de autor de Hispano-América (RefHispAm)

- Referência de autor de outra língua/localização, em regra de língua inglesa (RefOutros)

- Referência de autor do espaço lusófono que não Portugal ou Brasil (RefLusof)

Em relação ao uso destas categorias, foram tomadas algumas decisões metodológicas, obviamente discutíveis e que cabe explicitar:

1. Artigos - não foram considerados os editoriais, as recensões, as entrevistas, as resenhas, etc., mas apenas os artigos no chamado formato IMRAD (Introdução, Métodos, Resultados e Discussão - a que se juntam o Resumo, as Palavras-chave e as Referências), ou noutro formato análogo.

2. Autores - no caso de haver vários autores, incluindo de nacionalidades diversas (casos raros), teve-se conta apenas o primeiro autor.

3. Referências - no caso de haver vários autores, incluindo de nacionalidades diversas (casos raros), considerou-se apenas o primeiro autor.

\section{RESULTADOS}

Apresentamos, em seguida, os resultados da análise de conteúdo realizada aos artigos das oito revistas. Para maior facilidade, dividimos essa apresentação em três secções, correspondentes às três classes das nossas categorias de análise, a saber: 1. Línguas, 2. Autores, 3. Referências.

\section{LÍNGUAS}

Como se pode verificar na Tabela 2 (abaixo), a prática quase unânime é a da publicação do resumo na língua nacional da revista (português ou espanhol) e, simultaneamente, em inglês.

\begin{tabular}{|c|c|c|c|c|c|c|c|}
\hline \multirow{2}{*}{ País } & \multirow{2}{*}{ ReVISta } & \multicolumn{5}{|c|}{ LínGUAS DO RESUMO } & \multirow{2}{*}{ TOTAL } \\
\hline & & EsP+ING & FR+PORT+ING & ING & PORT & PORT+ING & \\
\hline \multirow{4}{*}{ Portugal } & Comunicação e Sociedade & o & o & o & o & 12 & 12 \\
\hline & Estudos em Comunicação & $\mathrm{O}$ & $\mathrm{O}$ & 2 & 1 & 4 & 7 \\
\hline & Prisma & $\circ$ & $\circ$ & ० & o & 7 & 7 \\
\hline & Subtotal & o & ० & 2 & 1 & 23 & 26 \\
\hline \multirow{4}{*}{ BRASIL } & Contemporanea & $\mathrm{O}$ & 1 & $\mathrm{O}$ & $\mathrm{O}$ & 13 & 7 \\
\hline & Eco-Pós & o & o & o & o & 8 & 7 \\
\hline & Matrizes & o & o & o & o & 15 & 15 \\
\hline & Subtotal & o & 1 & o & o & 36 & 37 \\
\hline \multirow{2}{*}{ ESPANHA } & Comunicación y Sociedad & 10 & o & $\mathrm{O}$ & o & $\mathrm{O}$ & 10 \\
\hline & Comunicar & 20 & 0 & 0 & o & $\mathrm{O}$ & 20 \\
\hline
\end{tabular}




\begin{tabular}{ccccccc}
\hline Subtotal & 30 & 0 & 0 & 0 & 0 & 30 \\
\hline Total & 30 & 1 & 2 & 1 & 59 & 93 \\
\hline \multicolumn{7}{c}{ Tabela 2: Línguas do resumo do artigo }
\end{tabular}

Já no que se refere ao texto do artigo, e como o evidencia a Tabela 3, podemos agrupar as revistas em três grupos diferentes:

1. As que publicam praticamente apenas na língua nacional, no caso o português (Prisma, de Portugal, e Contemporanea e Eco-Pós, do Brasil);

2. As que publicam maioritariamente na língua nacional, mas também em inglês (Estudos em Comunicação, de Portugal, e Comunicación y Sociedad², de Espanha);

3. As que publicam simultaneamente na língua nacional e em inglês (Comunicação e Sociedade, de Portugal, Matrizes, do Brasil, e Comunicar, de Espanha).

\begin{tabular}{|c|c|c|c|c|c|c|c|c|}
\hline \multirow{2}{*}{ País } & \multirow{2}{*}{ ReVISTA } & \multicolumn{6}{|c|}{ LínGUAS DO TEXTO } & \multirow{2}{*}{ TOTAL } \\
\hline & & Esp & EsP+ING & FR & ING & PORT & PORT+ING & \\
\hline \multirow{4}{*}{ PORTUGal } & Comunicação e Sociedade & o & o & o & o & o & 12 & 12 \\
\hline & Estudos em Comunicação & o & o & o & 2 & 5 & o & 7 \\
\hline & Prisma & o & o & o & o & 7 & o & 7 \\
\hline & Subtotal & o & o & o & 2 & 12 & 12 & 26 \\
\hline \multirow{4}{*}{ BRASIL } & Contemporanea & o & o & 1 & o & 13 & o & 14 \\
\hline & Eco-Pós & o & o & o & o & 8 & o & 8 \\
\hline & Matrizes & o & o & o & o & o & 15 & 15 \\
\hline & Subtotal & o & o & 1 & o & 36 & o & 37 \\
\hline \multirow{4}{*}{ ESPANHA } & Comunicación y Sociedad & 4 & o & o & 6 & 0 & 0 & 10 \\
\hline & Comunicar & 0 & 20 & 0 & 0 & 0 & 0 & 20 \\
\hline & Subtotal & 4 & 20 & 0 & 6 & o & o & 0 \\
\hline & TOTAL & 4 & 20 & 1 & 8 & 48 & 12 & 93 \\
\hline
\end{tabular}

Tabela 3: Línguas do texto dos artigos

\section{Autores}

A Tabela 4 (abaixo) apresenta os autores dos artigos publicados nas revistas de Portugal, Brasil e Espanha agregados por nacionalidade/local. As revistas dos três países apresentam situações relativamente diferentes:

1. Portugal - a autoria encontra-se distribuída entre Portugal e Brasil em partes quase iguais e, em menor grau, entre autores de outras nacionalidades;

2. Brasil - a autoria é quase exclusivamente brasileira, com presenças pouco consideráveis de autores de outras nacionalidades;

3. Espanha - a situação é análoga à do Brasil, embora a representação nacional seja um pouco mais mitigada, devido, em parte, à presença de autores hispano-americanos, também falantes de espanhol.

No entanto, os resultados ganham outro significado se cruzarmos as duas línguas em presença: o português e o espanhol. Assim, no conjunto das revistas de Portugal e

\footnotetext{
${ }^{2}$ A revista Comunicación y Sociedad tem edição bilingue deste outubro de 2014 (Comunication Q Society).
} 
do Brasil (63 artigos) existem dois autores espanhóis e um hispano-americano. No caso das revistas de Espanha (30 artigos), não há qualquer autor português ou brasileiro.

\begin{tabular}{|c|c|c|c|c|c|c|c|c|c|c|c|c|}
\hline \multirow{2}{*}{$\begin{array}{c}\text { REVISTAS } \\
\text { DE... }\end{array}$} & \multicolumn{2}{|c|}{ AutPort } & \multicolumn{2}{|c|}{ AutBrasil } & \multicolumn{2}{|c|}{ AutEsp } & \multicolumn{2}{|c|}{ AutIHispAм } & \multicolumn{2}{|c|}{ AutOutro } & \multicolumn{2}{|c|}{ TOTAL } \\
\hline & FREQ & $\%$ & FREQ & $\%$ & FREQ & $\%$ & FREQ & $\%$ & FREQ & $\%$ & FREQ & $\%$ \\
\hline PORTUGal & 11 & 42,31 & 9 & 34,62 & 1 & 3,85 & o & 0,00 & 5 & 19,23 & 26 & 100 \\
\hline BRASIL & o & 0,00 & 31 & 83,78 & 1 & 2,70 & 1 & 2,70 & 4 & 10,81 & 37 & 100 \\
\hline ESPANHA & $\circ$ & 0,00 & 0 & 0,00 & 23 & 76,67 & 3 & 10,00 & 4 & 13,33 & 30 & 100 \\
\hline TOTAL & 11 & 11,83 & 40 & 43,01 & 25 & 26,88 & 4 & 4,30 & 13 & 13,98 & 93 & 100 \\
\hline
\end{tabular}

\section{REFERÊNCIAS}

Em matéria de referências dos artigos, a Tabela 5 (abaixo) permite verificar que as revistas dos três países têm em comum o facto de o maior número de referências (à volta de $60 \%$ ) se reportar a autores não falantes da língua nacional, isto é, a autores de língua inglesa.

Seguem-se, depois, por ordem de importância: i) Nas revistas de Portugal, as referências de autores de Portugal (19,59\%) e do Brasil (18,28\%); ii) Nas revistas do Brasil, as referências de autores do Brasil (31,07\%); iii) Nas revistas de Espanha, as referências de autores de Espanha (30,30\%). Em todos os casos que não estes, o valor das referências a outros autores não ultrapassa os 5,19\% (valor das referências de autores hispano-americanos em revistas de Espanha).

\begin{tabular}{|c|c|c|c|c|c|c|c|c|c|c|c|c|c|c|}
\hline \multirow{2}{*}{$\begin{array}{c}\text { Revistas } \\
\text { DE... }\end{array}$} & \multicolumn{2}{|c|}{ REFPORT } & \multicolumn{2}{|c|}{ RefBrASIL } & \multicolumn{2}{|c|}{ REFEsP } & \multicolumn{2}{|c|}{ RefHISPAM } & \multicolumn{2}{|c|}{ REFOUtros } & \multicolumn{2}{|c|}{ RefLusof } & \multicolumn{2}{|c|}{ TOTAL } \\
\hline & FreQ & Perc. & FreQ & Perc. & FrEQ & Perc. & FreQ & Perc. & FreQ & Perc. & FreQ & Perc. & FreQ & Perc. \\
\hline PORTUGal & 180 & 19,59 & 168 & 18,28 & 45 & 4,90 & 8 & 0,87 & 516 & 56,15 & 2 & 0,22 & 919 & 100 \\
\hline BRASIL & 21 & 2,42 & 274 & 31,07 & 30 & 3,45 & 39 & 4,49 & 501 & 57,65 & 4 & 0,46 & 869 & 99,54 \\
\hline ESPANHA & 4 & 0,35 & o & 0,00 & 350 & 30,30 & 60 & 5,19 & 741 & 64,16 & o & 0,00 & 1155 & 100 \\
\hline TOTAL & 205 & 6,97 & 442 & 15,02 & 425 & 14,44 & 107 & 3,64 & 1758 & 59,73 & 6 & 0,20 & 2943 & 100 \\
\hline
\end{tabular}

Essas mesmas tendências confirmam-se ao efetuar-se o cruzamento entre autores e referências, tal como se mostra na Tabela 6: para além das referências maioritárias de autores que não são de língua portuguesa ou espanhola por parte dos autores de língua portuguesas ou espanhola (média de 59,73\%), os autores de cada língua tendem a escoIher referências dessa língua e, mesmo nessa, escolhem autores sobretudo do seu próprio país. Verifica-se, também, que os autores de outras línguas que não a portuguesa ou a espanhola - e que são maioritariamente de língua inglesa - praticamente não referem autores destas línguas (apenas o fazem em 5,25\% de casos) - apesar de serem objeto de referência, em média, em 59,73\% dos casos. 


\begin{tabular}{|c|c|c|c|c|c|c|c|c|c|c|c|c|c|c|c|}
\hline \multirow{2}{*}{$\begin{array}{l}\text { AUTORES / } \\
\text { REFERÊN- } \\
\text { CIAS }\end{array}$} & \multirow{2}{*}{$\begin{array}{l}\text { ARTI- } \\
\text { GOS }\end{array}$} & \multicolumn{2}{|c|}{ REFPORT } & \multicolumn{2}{|c|}{$\begin{array}{c}\text { REF- } \\
\text { BRASIL }\end{array}$} & \multicolumn{2}{|c|}{ RefEsp } & \multicolumn{2}{|c|}{$\begin{array}{l}\text { REFHIS- } \\
\text { PAM }\end{array}$} & \multicolumn{2}{|c|}{$\begin{array}{l}\text { REFOU- } \\
\text { TROS }\end{array}$} & \multicolumn{2}{|c|}{ RefLusof } & \multicolumn{2}{|c|}{ TOTAL } \\
\hline & & $\mathrm{FQ}^{\mathrm{A}}$ & Perc. & $\mathrm{FQ}^{\mathrm{A}}$ & Perc. & $\mathrm{FQ}^{\mathrm{A}}$ & Perc. & $\mathrm{FQ}^{\mathrm{A}}$ & $\%$ & $\mathrm{FQ}^{\mathrm{A}}$ & Perc. & $\mathrm{FQ}^{\mathrm{A}}$ & Perc. & $\mathrm{FQ}^{\mathrm{A}}$ & Perc. \\
\hline AUTPORT & 11 & 121 & 27,69 & 53 & 12,13 & 27 & 6,18 & 1 & 0,23 & 222 & 50,80 & 2 & 0,46 & 437 & 97,48 \\
\hline AutBrasi & 40 & 79 & 8,16 & 384 & 39,67 & 34 & 3,51 & 30 & 3,10 & 397 & 41,01 & 4 & 0,41 & 968 & 95,87 \\
\hline AutEsp & 25 & 4 & 0,40 & O & 0,00 & 336 & 33,63 & 30 & 3,00 & 604 & 60,46 & 0 & 0,00 & 999 & 97,50 \\
\hline $\begin{array}{l}\text { AutlHis- } \\
\text { PAM }\end{array}$ & 4 & o & 0,00 & 2 & 1,46 & 21 & 15,33 & 44 & 32,12 & 66 & 48,18 & 0 & ০,০০ & 137 & 97,08 \\
\hline AutOutro & 13 & 1 & 0,20 & 3 & 0,61 & 7 & 1,41 & 2 & 0,40 & 469 & 94,75 & $\circ$ & 0,00 & 495 & 97,37 \\
\hline TOTAL & 93 & 205 & 6,97 & 442 & 15,02 & 425 & 14,44 & 107 & 3,64 & 1758 & 59,73 & 6 & 0,20 & 2943 & 100,00 \\
\hline
\end{tabular}

\section{DisCUSSÃO E CONCLUSÕES}

O pequeno estudo que aqui apresentamos permitiu verificar duas tendências exploratórias principais nas revistas de Ciências da Comunicação de Portugal, Brasil e Espanha:

1 - Referência mútua entre autores da mesma língua e do mesmo país, verificando-se um reduzido cruzamento não só entre os autores da língua portuguesa e da língua espanhola e vice-versa, mas também dentro do português, entre os autores de Portugal e do Brasil.

2 - Predomínio de referência de autores de outras línguas, com larga preponderância do inglês pelos autores de língua portuguesa e espanhola - sem que a inversa se verifique.

Podemos extrair destas tendências/premissas, a conclusão geral de que, tal como se dá a entender logo no título deste texto, há, de facto, um desconhecimento recíproco dos investigadores ibero-americanos em Ciências da Comunicação. Um dos corolários desta conclusão é o de que, desse modo, os investigadores de Ciências da Comunicação de língua portuguesa e espanhola estão a dar o seu precioso contributo para reforçar o paradigma dominante - um paradigma baseado na publicação em inglês, em revistas maioritariamente inglesas ou americanas, indexadas em bases de dados como a Web of Science (Thomson Reuters) ou a Scopus (Elsevier) e que privilegiam claramente estudos de natureza empírica e quantitativa.

Como é óbvio, quer a nossa conclusão quer o seu corolário devem ser aceites com a consciência de que ambos se baseiam na análise de uma amostra de revistas/números restrita e limitada no espaço e no tempo.

No entanto, a serem aceites como válidos, não implicam que o desconhecimento mútuo seja uma fatalidade. Assim, a terminar, deixamos algumas propostas de ação tendentes a promover uma maior aproximação entre os investigadores ibero-americanos de Ciências da Comunicação:

1. Publicação, pelas revistas, dos resumos e dos textos em vernáculo e em inglês (português-inglês, espanhol-inglês) - algo que já acontece na generalidade das revistas em relação aos resumos, e nas revistas Comunicação e Sociedade, Matrizes e Comunicar também em relação aos textos. 
2. Publicação, pelas revistas, de números temáticos que envolvam investigadores dos vários países e das duas línguas.

3. Eventual estabelecimento, por cada umas das revistas, de uma quota de publicação para autores ibero-americanos de outras nacionalidades que não a da revista.

4. Realização de encontros científicos comuns centrados em temas específicos e dando origem a publicações conjuntas, nomeadamente números especiais de revistas.

5. Intensificação do intercâmbio de docentes e estudantes, a nível do ensino e da investigação, de forma a promover o conhecimento mútuo das línguas, das culturas e dos autores da área de Ciências da Comunicação.

\section{REFERÊNCIAS BIBLIOGRÁFICAS}

Barthes, R. (1968). Le bruissement de la langue. Paris: Seuil.

Barthes, R. (1988). O rumor da língua. São Paulo: Brasiliense.

DGEEC, Direção-Geral de Estatísticas da Educação e Ciência. (2015). Produção Científica. Retirado de http:// www.dgeec.mec.pt/np4/210/.

Dilthey, W. (1994). Introducción a las ciencias del espíritu. México: Fondo de Cultura Económica.

Foucaul, M. (2001). Dits et écrits, tome I - 1954-1988. Paris: Gallimard.

Foucault, M. (1992). O que é um autor? Lisboa: Passagem.

Garfield, E. (1955). Citation indexes for science: A new dimension in documentation through association of ideas. Science, 122(3159), 108-11.

Gil, F. (1989). Como pensa a língua. Análise, 12, 179-199.

Kant, I. (2001). Crítica da razão pura. Lisboa: Fundação Calouste Gulbenkian.

Martins, M.L. (2015). A liberdade académica e os seus inimigos. Comunicação e Sociedade, 27, 405-420.

Perelman, C. (1993). O império retórico. Porto: Edições Asa.

Popper, K. (1999). O mito do contexto. Lisboa: Edições 70.

PORDATA, Base de Dados Portugal Contemporâneo. (2015). Retirado de http://www.pordata.pt/Subtema/ Portugal/Publicacoes+Cientificas-83.

Ricoeur, P. (1995). Teoria da interpretação. Porto: Porto Editora.

Santos, B.S. (1993). Introdução a uma ciência pós-moderna. Porto: Afrontamento.

Santos, B.S. (2002). Um discurso sobre as ciências. Porto: Afrontamento.

\section{NOTA BIOGRÁFICA}

Paulo Serra é licenciado em Filosofia pela Faculdade de Letras de Lisboa e mestre, doutor e agregado em Ciências da Comunicação pela UBI, onde é professor catedrático 
no Departamento de Comunicação e Artes e investigador no LabCom.IFP. Exerce atualmente o cargo de presidente da SOPCOM. É autor dos livros A Informação como Utopia (1998), Informação e Sentido (2003), Manual de Teoria da Comunicação (2008) e coautor do livro Informação e Persuasão na Web (2009). É organizador e coorganizador de várias obras, a última das quais $A$ Televisão Ubíqua (2015). Tem ainda vários capítulos de livros e artigos publicados em obras coletivas e revistas.

E-mail: pserra@ubi.pt

Departamento de Comunicação e Artes, Universidade da Beira Interior, Rua Marquês D’Ávila e Bolama, 6201-001 Covilhã, Portugal.

* Submetido: 02-09-2015

* Aceite: 10-11-2015 